\title{
Electrostatic Stabilization and Characterization of Fine Ground Silicon Particles in Ethanol
}

\author{
Markus Nöske ${ }^{1}$ (1) $\cdot$ Sandra Breitung-Faes ${ }^{1} \cdot$ Arno Kwade $^{1}$
}

Received: 2 December 2018 / Accepted: 25 January 2019 / Published online: 31 January 2019

(C) The Author(s) 2019

\begin{abstract}
Stirred media milling is a common method for the efficient production of nanoparticles. Here the grinding of semi-metallic silicon nanoparticles is presented, which are of special interest as anode material for next generation lithium-ion batteries. Ground silicon particles show an enormous reactivity in water due to particle etching but only surficial oxidization in alcoholic solvents, which inhibits further particle etching. Therefore, the grinding process was realized in ethanol as a solvent in order to avoid particle etching but allow good integrity to a water-based anode production later on. From the application point of view the colloidal stability of silicon nanoparticle suspensions is of great importance, to realize anode coating structures with fine disperse silicon nanoparticles. Hence, this study is focusing on the electrostatic stabilization of the silicon nanoparticles in ethanol, which was characterized by zeta potential and the agglomerate size measurements. These results corresponding to electrostatical interactions are also in good accordance with rheological characterization of the suspensions and theoretical calculations. Additionally, the final metallic silicon content was also of high interest for the application, so that a thermogravimetric analysis procedure was established and evaluated by a chemical pulping procedure according to DIN EN ISO 21068-2. Furthermore the impact of the chosen stabilization additive and the solvent purity on the silicon content are discussed. Finally the process is realized by a pregrinding step in a planetary ball mill and a fine grinding step within a stirred media mill. With this setup a production route for suspensions with a median primary particle size of less than $150 \mathrm{~nm}$ and metallic silicon content above $80 \mathrm{wt} . \%$ of the particles is presented. The ground nanoparticles show a surficial oxidized shell with a silicon core and a flake-like shape with crystalline and amorphous regions.
\end{abstract}

Keywords Fine grinding $\cdot$ Silicon nanoparticles $\cdot$ Electrostatic stabilization $\cdot$ Surficial oxidation

\section{Introduction}

The application of nanoparticles with customized properties is common in a variety of industries [1-4]. The combination of nanoscale and material dependent characteristics is often the basis for innovations and enhanced product performances. Concerning this matter silicon offers several interesting opportunities. Due to its intrinsic photoluminescence which is increased by the quantum confinement effect with decreasing

Markus Nöske

m.noeske@tu-bs.de

1 Institute for Particle Technology, Technische Universität Braunschweig, Volkmaroder Strasse 5, 38104 Braunschweig, Germany particle size, it is a promising candidate for the usage in optoelectronics [5, 6]. In addition, the non-toxicity of pure silicon and its degradation product (orthosilicic acid) lead to many biomedical developments such as fluorescent biomarkers [7-9], drug delivery carrier [10,11] and silicon-based therapeutics [12]. In the semiconductor industry silicon is the main material due to its good semi- and photo-conducting properties, which can be adjusted by thermal treatment or elemental doping. The development of stable suspensions with silicon nanoparticles offers a multitude of applications in the field of printed electronics and solar cells in future [13-15]. Furthermore, theoretical ten-times higher specific capacity regarding the storage of lithium ions in an anode of a lithium-ion battery compared to graphite based anodes makes silicon a promising candidate for next generation lithium ion batteries [16-18].

In the present study the production of silicon nanoparticles in a two-step grinding procedure is established for the later 
application in anodes of lithium ion batteries. Zhang [19] and Liu [20] showed that reversible lithiation of silicon particles can be reached with a particle size below $150 \mathrm{~nm}$. Therefore, this particle size was adapted as a target size of the grinding process.

Taking into account common water-based anode processing, the mixable solvent ethanol was chosen to allow a good integrity of the silicon nanoparticles, which can be added as a ground, ethanolic silicon suspension directly to the aqueous anode suspension or previously used for the preparation of hydrophilic, silicon-based anode composites. Other advantages of this solvent are good availability and low costs for mass production in up scaled processes. Reindl et al. [21, 22] investigated the intrinsic stability and oxidation of silicon for printed electronics during dispersing in polar and non-polar solvents. They figured out that oxidation is always present in alcoholic solvents, which leads to the formation of a 1-2 nm thin oxide shell around the particles. In addition it was shown by Hou [17] that this oxide layer can have on the one hand positive effects on the battery performance regarding the cycle life of the silicon material. On the other hand a too high content of silicon oxide in the anode leads to high initial capacity losses of the battery cell due to irreversible formation of lithium silicates [16]. Thus, a range exists were fineness and silicon content of the particles are optimal for this application. In the present study the examination of the silicon oxidization in ethanol is done by Fourier-transform infrared spectroscopy, qualitatively. In addition, a thermogravimetric method is established and evaluated by a chemical pulping procedure according to DIN EN ISO $21068-2$ in order to quantify the metallic silicon content of the particles. The impact of chosen formulation components on the final metallic silicon content of different suspensions with the same fineness are investigated by this method.

Ashuri, He and Shaw [16] summarized production routes for promising silicon rich anodes. They figured out that for a good anode performance the nanoscale of the silicon building blocks in combination with good introduction into a porous carbon network with high electric conductivity and mechanical flexibility are necessary. To avoid particle agglomeration and to allow good integrity of the silicon nanoparticles during mixing steps with carbon materials the colloidal stability of the particles is crucial. However, a systematic study on the stabilization of silicon nanoparticles in ethanol is missing in literature. In this study stabilization investigations are carried out by adjustment of the zeta potential and thus by increasing the repulsive particle-particle interactions, electrostatically. The latter is described by the theory of Derjaguin, Landau, Verwey, Overbeek (DLVO theory) [23] and is in good accordance to the rheological behavior of the suspension.

\section{Material and Methods}

\subsection{Materials}

As feed material for the grinding experiments silicon powder from PyroPowders GmbH, Germany, with a purity of $>99.0 \%$ was used. The particle size distribution is given in Fig. 1 (analyzed by laser diffraction, sympatec Helos). The median particle size is $17 \mu \mathrm{m}$.

The solvents used in this study were absolute Ethanol (EtOH) from Merck KGaA, Germany, (purity 99.99\%) and Ethanol technical grade (EtOH tec) from Berkel AHK Alkoholhandel GmbH, Germany (purity $>96.0 \%$ ). For the stabilization of the silicon particles sodium hydroxide $(\mathrm{NaOH})$ from Merck KGaA, Germany, (purity $99.98 \%$ ) was utilized and added as a solution of $0.5 \mathrm{~mol} \mathrm{NaOH}$ in EtOH stepwise to the product suspension during the grinding experiment.

\subsection{Grinding Set-up}

Since the feed material was too coarse for the fine grinding procedure a pre-grinding step in a planetary ball mill PM 400 from Retsch GmbH, Germany, was performed upstream. The beads $(1.5 \mathrm{~mm})$ for this grinding procedure were made of tungsten carbide and obtained from Sigmund Lindner $\mathrm{GmbH}$, Germany. Milling processes were performed with a filling ratio of the beads in the steel vessels $(0.5 \mathrm{~L})$ of $30 \%$, a sun wheel speed of $250 \mathrm{rpm}$ and a grinding time of $1 \mathrm{~h}$. In each vessel $1228 \mathrm{~g}$ beads, $62.5 \mathrm{~g}$ silicon and $250 \mathrm{~g}$ ethanol were added successively. Thus, the ground ethanolic silicon suspensions had a solids content $\mathrm{c}_{\mathrm{m}}$ of $20 \mathrm{wt} . \%$. No additive was added during this step.

Fine grinding and stabilization investigations were performed with the stirred media mill SL-12-Nano from VMA Getzmann GmbH, Germany, which was operated in circuit mode between the mill and a stirred vessel. These experiments

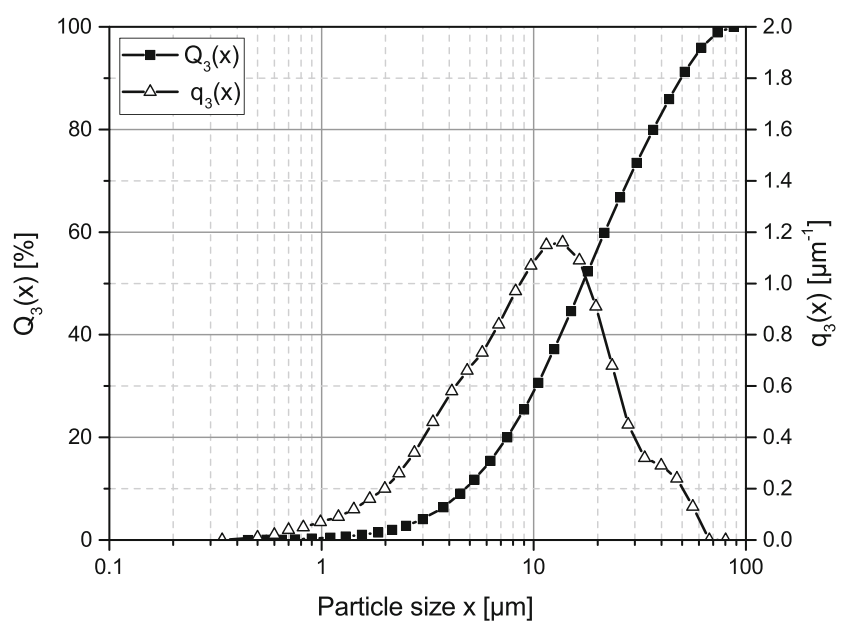

Fig. 1 Particle size distribution of silicon feed particles 
were run with yttrium stabilized zirconia beads $(315 \mu \mathrm{m})$ from Sigmund Lindner GmbH, Germany, a filling ratio of $70 \%$ and a stirrer circumferential speed of $8 \mathrm{~m} \cdot \mathrm{s}^{-1}$. After the experiment was started with a prefilling of $300 \mathrm{~g}$ ethanol, $300 \mathrm{~g}$ of the preground suspension was added to obtain a suspension with a solids content of $10 \mathrm{wt} \%$. During the experiment the $\mathrm{pH}^{*}$ value was measured repeatedly and adjusted by pipetting ethanolic $\mathrm{NaOH}$ solution into the suspension stirred inside the circuit vessel.

The power draw $\mathrm{P}$ of the mill during the process time $\mathrm{t}$ was measured, as well as the no load power $\mathrm{P}_{0}$ afterwards. Under consideration of the ground solids mass $\mathrm{m}$ the specific energy input $\mathrm{E}_{\mathrm{m}}$ is calculated according to eq. 1 .

$\mathrm{E}_{\mathrm{m}}=\frac{\int_{0}^{\mathrm{t}}\left(\mathrm{P}(\mathrm{t})-\mathrm{P}_{0}\right) \cdot \mathrm{dt}}{\mathrm{m}}$

\subsection{Analysis}

\subsubsection{Particle Size and Morphology}

The primary particle size was analyzed by acoustic spectroscopy (acoustic) with the DT1200 of Quantachrome GmbH \& Co. KG, Germany, in suspensions with original solids content. For the evaluation of the agglomerate size diluted samples using the dynamic light scattering (DLS) device Nanophox from Sympatec GmbH, Germany, was applied. The morphology of the ground product was characterized by electron microscopy with a scanning electron microscope (SEM) LEO 1550 from Carl Zeiss AG, Germany, and a transmission electron microscope (TEM) FEI Tecnai G2 F20, FEI Technologies Inc., USA. In addition, the median crystallite size of selected samples was analyzed by X-ray diffraction (XRD) using Empyrean series 2 with PIXcel-3D detector, PANalytical, Germany.

\subsubsection{Particle Surface Characterization}

The zeta potential $\zeta$ was investigated by measuring the colloid vibration current in the undiluted suspension with the DT1200 of Quantachrome GmbH \& Co. KG, Germany. After the grinding experiments $20 \mathrm{ml}$ of the suspension was centrifuged and dried carefully by vacuum evaporation at room temperature to obtain dry silicon powders. These powders were ground in mortar and analyzed by Fourier-transform infrared spectroscopy (FT-IR) using ATR Vertex V70 from Bruker AXS Inc., USA.

\subsubsection{Suspension Characterization}

The dynamic viscosity was characterized as a function of the shear rate by a rotational viscometer Gemini 2 from
Malvern Instruments Ltd., Great Britain. In addition, the $\mathrm{pH}$ value analysis in ethanolic suspensions was carried out according to Barth [24] and Menon [25]. They mentioned that the $\mathrm{pH}$ value is originally defined for aqueous systems, but can be adapted to water-similar media like ethanol. The dissociation constant of ethanol is $10^{-19.1} \mathrm{~mol}^{2} \cdot \mathrm{L}^{-2}$ and therefore, the $\mathrm{pH}$ scale ranges to 19.1 [26]. For the analysis of the $\mathrm{pH}$ value in ethanol no specific sensor or ethanol-based calibration standards were available. Thus, the $\mathrm{pH}$ analysis was carried out with a standard $\mathrm{pH}$ electrode for aqueous systems. However, we are aware the resulting measured values are not correct from their absolute value and should only be compared to each other. The electrode WTW SenTix 41 from Xylem Analytics Germany Sales GmbH \& Co. KG, Germany, was used and calibrated with aqueous standard solutions. $\mathrm{pH}$ values analyzed in this way were marked with $\mathrm{pH}^{*}$.

\subsubsection{Quantification of Metallic Silicon Content}

For the quantification of the metallic silicon content a thermogravimetric analysis (TGA) method was developed and evaluated with a chemical pulping procedure according to DIN EN ISO 21068-2 (pulping). For the development of the TGA method, nano-ground silicon samples were first treated in a TGA/DSC-Analyzer from Mettler Toledo Inc., Switzerland, for the documentation of trends during the treatment. In a second step the evaluated procedure was transferred to a procedure in a muffle furnace from Nabertherm $\mathrm{GmbH}$, Germany. Details about the developed method are presented later on in section 3.3.

\section{Results and Discussion}

\subsection{Silicon Stabilization}

During fine grinding of silicon in ethanol the particles tend to form agglomerates as a result of increasing ratio of attractive van der Waals forces to buoyancy and fluid forces due to the decreasing particle sizes. For aqueous systems the electrostatic stabilization of the ground particles due to the analysis and adjustment of the zeta potential $\zeta$ is a commonly known technique [27]. The latter can be adapted to ethanolic systems by manipulating the $\mathrm{pH}^{*}$ value of the suspension [24]. Therefore, the dependency of both parameters was analyzed and illustrated in Fig. 2. The suspension without any additive has a $\mathrm{pH}^{*}$ of 4.9 and $\mathrm{a} \zeta$ of $-15 \mathrm{mV}$ after fine grinding. By increasing the $\mathrm{pH}^{*}$ value to 7.5 the $\zeta$ becomes enhanced to $-45 \mathrm{mV}$ and is only slightly decreasing by further increase of the $\mathrm{pH}^{*}$ value to 11 . Based on this findings grinding experiments with three different $\mathrm{pH}^{*}$ values $(5,7.5$ and 10$)$ had been carried out with equal specific energy input of $33,000 \mathrm{~kJ} \cdot \mathrm{kg}^{-1}$. The ground suspensions exhibit only negligible deviation from the median 


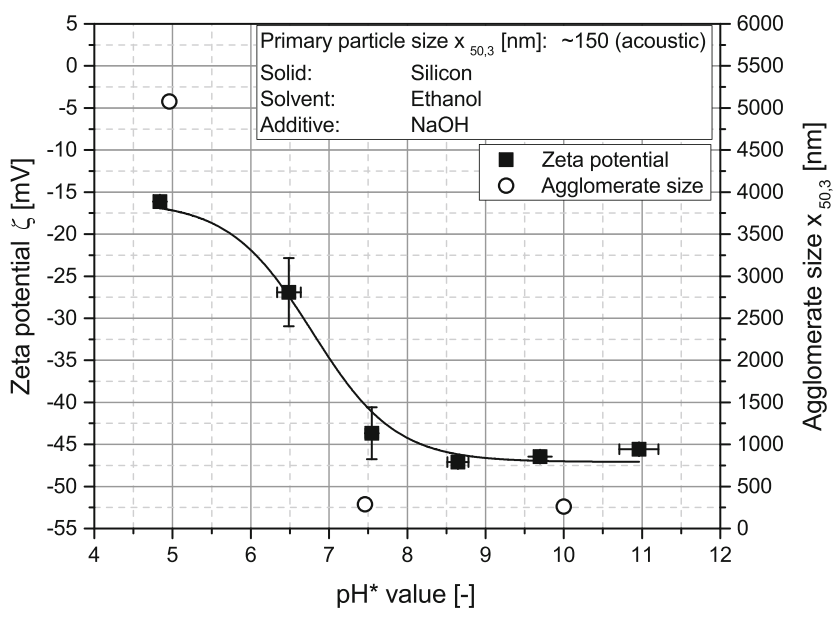

Fig. 2 Zeta potential $\zeta$ and agglomerate size dependent from the $\mathrm{pH}^{*}$ value for silicon nanoparticles in ethanol

primary particle size of $150 \mathrm{~nm}$, which was analyzed by acoustic spectroscopy and was set as the target size. By comparison of the median agglomerate size, measured by DLS, and the median primary particle size an indication of the colloidal stability can be obtained (Fig. 2). It becomes obvious, that at $\mathrm{pH}^{*} 5$ the particles are highly agglomerated, because a median agglomerate size of $5 \mu \mathrm{m}$ was detected. This size can be reduced to $280 \mathrm{~nm}$ due to an increase of $\zeta$ at $\mathrm{pH}^{*} 7.5$ and $\mathrm{pH}^{*} 10$. Therefore, in a $\mathrm{pH}^{*}$ range from 7.5 to 10 a small discrepancy of the agglomerate size from the primary particle size was found. This result can be explained by the different measurement techniques and it can be assumed that agglomeration is almost negligible.

In order to reach a better understanding with respect to the surficial reactions, which are occurring between reactive surfaces of ground silicon particles and solvent molecules, FT-IR spectra of dried samples from ground silicon and the untreated feed material were compared. The results are presented in Fig. 3. The surficial oxidation of the particles is clearly

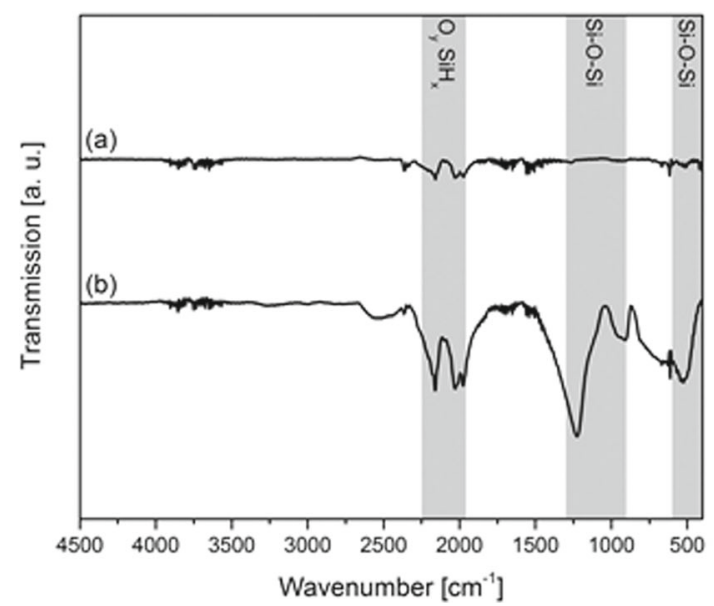

determined due to the presence of typical adsorption bands. Si-O-Si bands are detected from 900 to $1300 \mathrm{~cm}^{-1}$ [28] and around $500 \mathrm{~cm}^{-1}[21,22]$. Additionally $\mathrm{O}-\mathrm{SiH}$ groups are determined by several bands in a range from 2000 to $2250 \mathrm{~cm}^{-1}$ [28]. The reaction mechanism between silicon and alcohol was shown by Wayner et al. [29] and is also presented in Fig. 3. They outlined that this mechanism is similar to the reaction with water, but in contrast alcohols do not etch the silicon material [30]. Therefore, a thin oxide layer on the particle surface is formed, as well as hydrogen gas which has to be aspirated for safety reasons.

These experimental findings can be summarized and described with respect to colloidal stability issues more detailed with the DLVO theory [23]. The validity of this theory for ethanolic suspension systems was already shown [24, 31]. Wang et al. [31] described an pH-dependent surface charge of alumina particles in ethanol, which can be transferred for surficial oxidized silicon particles with silanol surface groups $(\mathrm{SiOH})$ in basic $\mathrm{pH}$ environment in the following way:

$\mathrm{SiOH}+\mathrm{OH}^{-} \leftrightarrow \mathrm{SiO}^{-}+\mathrm{H}_{2} \mathrm{O}$

The total interaction potential $V_{\text {tot }}$ of two silicon particles is the sum of the attractive van der Waals potential $V_{A}$ and the repulsive electrostatic potential $V_{R}$.

$\mathrm{V}_{\text {tot }}=\mathrm{V}_{\mathrm{A}}+\mathrm{V}_{\mathrm{R}}$

$\mathrm{V}_{\mathrm{A}}$ between two particles of equal size can be calculated by the following equation [32]:

$\mathrm{V}_{\mathrm{A}}=-\mathrm{A} \cdot \frac{1}{6}\left(\frac{2}{\mathrm{~s}^{2}-4}+\frac{2}{\mathrm{~s}^{2}}+\ln \frac{\mathrm{s}^{2}-4}{\mathrm{~s}^{2}}\right)$

$\mathrm{V}_{\mathrm{A}}$ depends on the particle radius $\mathrm{r}$ and the distance between the particles a. Both parameters are included in the parameter s.

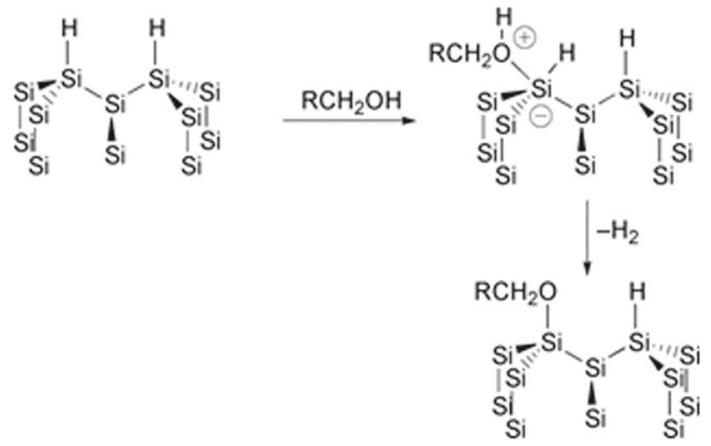

Fig. 3 Left: FT-IR spectra of (a) feed material and (b) fine ground silicon particles in ethanol ( $\mathrm{x}_{50,3}: 150 \mathrm{~nm}$, acoustic) with typical IR absorption bands [21, 22, 28]; right: Reaction between alcohol and silicon [29] 
$\mathrm{s}=\frac{(\mathrm{a}+2 \cdot \mathrm{r})}{\mathrm{r}}$

Furthermore, $V_{A}$ is a material function due to the fact, that the Hamaker constant A is only dependent on material parameters of the dispersed solid $\mathrm{A}_{\mathrm{s}}$ and the fluid $\mathrm{A}_{\mathrm{f}}$ :

$A=\left(\sqrt{A_{s}}-\sqrt{A_{f}}\right)^{2}$

For the calculation of the Hamaker constant a value of 6.3 for silica, which represents the surficial oxidized particle surface [33], and 4.2 for ethanol were used, respectively [34].

The colloidal stability of a suspension can be enhanced by an increase of the repulsive electrostatic potential $\mathrm{V}_{\mathrm{R}}[24,27,31]$.

$\mathrm{V}_{R}=\frac{r}{v^{2}} \cdot \frac{32 \cdot \pi \cdot \varepsilon \cdot \varepsilon_{0} \cdot(R \cdot T)^{2}}{F^{2}} \cdot \gamma^{2} \cdot e^{-\kappa \cdot a}$

The repulsive potential $V_{R}$ was calculated by the particle radius $\mathrm{r}$, which was half of the particle diameter $\mathrm{x}_{50,3}$ of $150 \mathrm{~nm}$. Furthermore, the dielectric coefficient of EtOH $(24.35[35]) \varepsilon$, the relative permittivity $\left(8.85 \cdot 10^{-12}\right.$ $\left.\mathrm{C} \cdot \mathrm{V}^{-1} \cdot \mathrm{m}^{-1}\right) \varepsilon_{0}$, the gas constant $\left(8.314472 \mathrm{~J} \cdot \mathrm{Kmol}^{-1}\right) \mathrm{R}$ and the Faraday constant $\left(9.65 \cdot 10^{4} \mathrm{C} \cdot \mathrm{mol}^{-1}\right) \mathrm{F}$ were used. A temperature $\mathrm{T}$ of $293.15 \mathrm{~K}$ was also included. The valence of the $\mathrm{OH}^{-}$and $\mathrm{Na}^{+}$ions $\mathrm{v}$ was set equal to 1 . Taken into account, that the surficial potential $\Psi_{0}$ can be replaced by $\zeta$ in good approximation [24, 31], $\gamma$ was calculated by the following equation:

$\gamma=\frac{\left(\mathrm{e}^{\left(\frac{\mathrm{v} \cdot \mathrm{F} \cdot \mathscr{W}_{0}}{\mathrm{R} \cdot \mathrm{T}}\right)-1}\right)}{\left(\mathrm{e}^{\left(\frac{v \cdot \mathrm{F} \cdot \mathrm{F}_{0}}{\mathrm{R} \cdot \mathrm{T}}\right)+1}\right)}$

The Debye parameter к can be calculated by consideration of the ionic concentration $\mathrm{c}$ by:

$\kappa=\sqrt{\frac{2 \cdot F^{2} \cdot c \cdot v^{2}}{\varepsilon \cdot \varepsilon_{0} \cdot R \cdot T}}$

Furthermore, the thermic energy has to be considered for the stability of a suspension. Verwey and Overbeek [23] assumed in a first approximation a good colloidal stability for a total interaction potential $\mathrm{V}_{\text {tot }}$ of higher than $10 \mathrm{k} \cdot \mathrm{T}$. For this term the Boltzmann constant $\mathrm{k}$ has to be considered $\left(1.38064852 \cdot 10^{-23} \mathrm{~J} \cdot \mathrm{K}^{-1}\right)$. More current investigations prove a stable colloidal system for $\mathrm{V}_{\text {tot }}>15 \mathrm{k} \cdot \mathrm{T}[23,27,32]$. In order to compare $V_{\text {tot }}$ and the thermic energy more easily, $V_{\text {tot }}$ was normalized by dividing it by $\mathrm{k} \cdot \mathrm{T}$. The resulting Potential curves for suspensions with three different $\mathrm{pH}^{*}$ values are shown in Fig. 4 (left) as well as the corresponding rheological behavior of the suspensions (right).
The potential curve of the suspension with $\mathrm{pH}^{*} 5$ has a maximum normalized interaction potential of 5 , which proves the poor colloidal stability due to the absence of a significant potential barrier against particle agglomeration. This finding correlates with a pronounced shear thinning viscosity behavior due to a high level of internal friction. It is also shown, that the colloidal stability can be effectively increased by shifting the $\mathrm{pH}^{*}$ value to 7.5 , which corresponds to a normalized interaction potential of almost 40 and a nearly Newtonian viscosity behavior. By further increase of the $\mathrm{pH}^{*}$ value the $\zeta$ decreases only slightly (Fig. 2) but the ionic concentration $c$ increases conversely. Therefore, the diffuse double layer close to the particles becomes less extended and as a result the potential curve is also compressed, reaching a maximum value of still more than 30 . The attraction between the particles becomes higher and can be detected by a shear thinning rheological behavior of the suspension.

\subsection{Silicon Grinding}

Based on the stabilization investigations which show a clear optimum of increased repulsive particle-particle interaction at a $\mathrm{pH}^{*}$ value of 7.5 , the same stabilization was used for fine grinding tests in a stirred media mill. The results of the twostep grinding procedure are shown in Fig. 5.

The grinding results show a clear correlation of particle size reduction and increasing specific energy input. After the pregrinding step the median particle size $\mathrm{x}_{50,3}$ has a value of $500 \mathrm{~nm}$ correlating with a specific energy of $2100 \mathrm{~kJ} \cdot \mathrm{kg}^{-1}$. Additionally, the particle size distribution shows a wide range represented by the values of top cut $x_{90,3}$ of $1500 \mathrm{~nm}$ and the fines $\mathrm{x}_{10,3}$ of $180 \mathrm{~nm}$, respectively. The top cut was small enough after this step, that blocking of the flat screen, used for internal grinding media separation, during the fine grinding process could be avoided. At the end of the fine grinding process step i.e. after a specific energy input of 106,000 $\mathrm{kJ}^{\mathrm{k}} \cdot \mathrm{kg}^{-1}$ the $\mathrm{x}_{50,3}$ can be reduced further to a value of $75 \mathrm{~nm}$. The particle size distribution becomes narrow shown by the $\mathrm{x}_{90,3}$ and $\mathrm{x}_{10,3}$ values of $190 \mathrm{~nm}$ and $45 \mathrm{~nm}$, respectively.

In order to get impressions of the particle shape resulting from the grinding process SEM and TEM images of feed material and the ground silicon particles are shown in Fig. 6. The feed material in this study is a coarse powder with an angular particle shape (a). After a specific energy input of $\sim 33,000 \mathrm{~kJ} \cdot \mathrm{kg}^{-1}$ ground silicon particles with a measured $\mathrm{x}_{50,3}$ of $\sim 150 \mathrm{~nm}$ show a flake-like particle shape (b). The diameter of a single flake plane can be attributed to the measured particle sizes in good accordance. Therefore, the particle size measured with acoustic spectroscopy can be defined as the primary particle size in this case. TEM analyses also convey the impression of a thin layered flake structure (c) with amorphous and crystalline regions (d). Hou et al. report [17] about significant amorphization of silicon particles during the 
milling process, which can be seen in amorphous regions between grain boundaries. This observation can be confirmed by amorphous and crystalline regions, which are marked in Fig. $6 \mathrm{~d}$, inside the nanoparticle. In addition, XRD analyses show that the median crystallite size of the feed material can be reduced from $100 \mathrm{~nm}$ to $53 \mathrm{~nm}$ after the pre-grinding and further on to $10 \mathrm{~nm}$ after the fine grinding step. Besides it can be pointed out that in contrast to dispersing of silicon aggregates, where the particles have a spherical shape $[18$, 21], the thickness of the flake-like particles seem to be in the lower nanometer range.

\subsection{Silicon Content Analysis}

Regarding the usage of the silicon nanoparticles in anode production for lithium ion batteries Hou [17] and Tao [36] pointed out, that the amount of oxidized silicon on the one hand can lower the initial start capacity of a battery cell, while on the other hand the mechanical strength of the particles increases as well as the cycle stability of the material. During the grinding process mechanical stressing events cause the generation of fresh and unsaturated silicon surfaces after a breakage event. These surfaces are mainly saturated by oxidation reaction with solvent molecules [21] (see also Fig. 3). In order to quantify the amount of non-degraded metallic silicon content of the nanoparticles a TGA procedure was established in this work. In Fig. 7 a typical behavior of a fine ground silicon sample during the TGA procedure is shown.

The sample mass $\mathrm{m}_{\mathrm{s}}$ was heated up under nitrogen flow in a range of $20-950^{\circ} \mathrm{C}$ and held at $950^{\circ} \mathrm{C}$ for $2 \mathrm{~h}$. During this treatment a small mass loss $\mathrm{m}_{\text {loss }}$ of $2 \mathrm{wt} . \%$ between 20 and $200{ }^{\circ} \mathrm{C}$, indicating organic residuals from the grinding procedure, and a high mass increase in a range of 50-60 wt.\% during the holding phase at $950{ }^{\circ} \mathrm{C}$ is detected. The mass increase during the holding phase is attributed to the formation

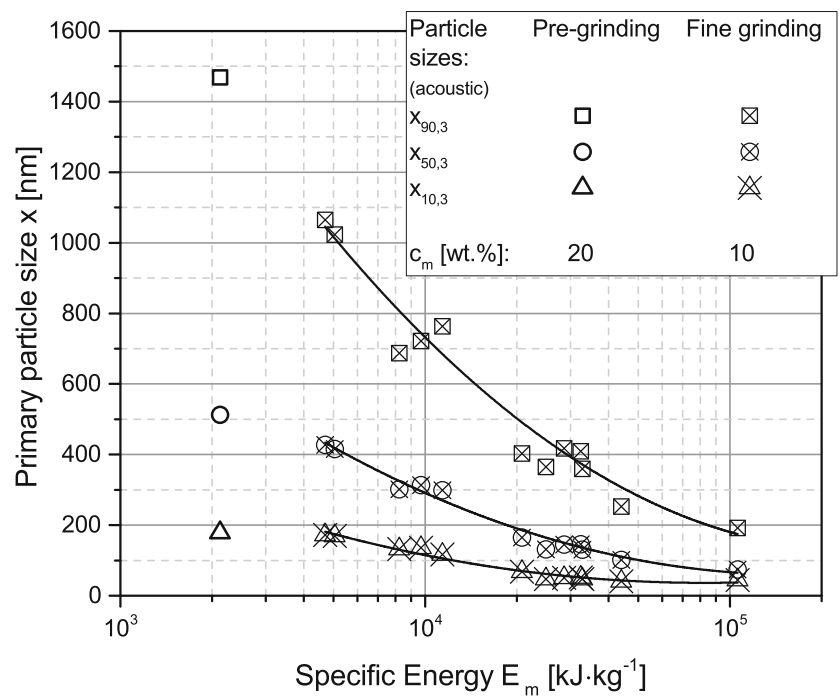

Fig. 5 Particle sizes $\mathrm{x}_{90,3}, \mathrm{x}_{50,3}$ and $\mathrm{x}_{10,3}$ after pre-grinding and during fine grinding measured with acoustic spectroscopy and dependent on the specific energy $E_{m}$

of silicon nitride $\left(\mathrm{Si}_{3} \mathrm{~N}_{4}\right)$ during the melting of silicon nanoparticles, which starts at temperatures above $800{ }^{\circ} \mathrm{C}$. This phenomena was already published by Schierning [37] and Rieke [15], who showed that the melting temperature of silicon nanoparticles is extremely reduced compared to silicon bulk material at $1410^{\circ} \mathrm{C}$. Furthermore, there were no reactions between a silicon dioxide $\left(\mathrm{SiO}_{2}\right)$ reference sample and nitrogen examined (see Fig. 7), which leads to the conclusion that any $\mathrm{SiO}_{2}$ content in the initial sample does not taking active part on reactions during this procedure. After this sample behavior was clarified, the TGA procedure was transferred to a muffle furnace with nitrogen flushing. The mass loss $\mathrm{m}_{\text {loss }}$ after $200{ }^{\circ} \mathrm{C}$ and the increased mass $\mathrm{m}_{\text {incr }}$ after an expanded holding phase of $5 \mathrm{~h}$ at $950^{\circ} \mathrm{C}$ were measured separately.

For the calculation of the silicon content the inorganic sample mass $\mathrm{m}_{\mathrm{s}, \text { inorg }}$ was calculated.
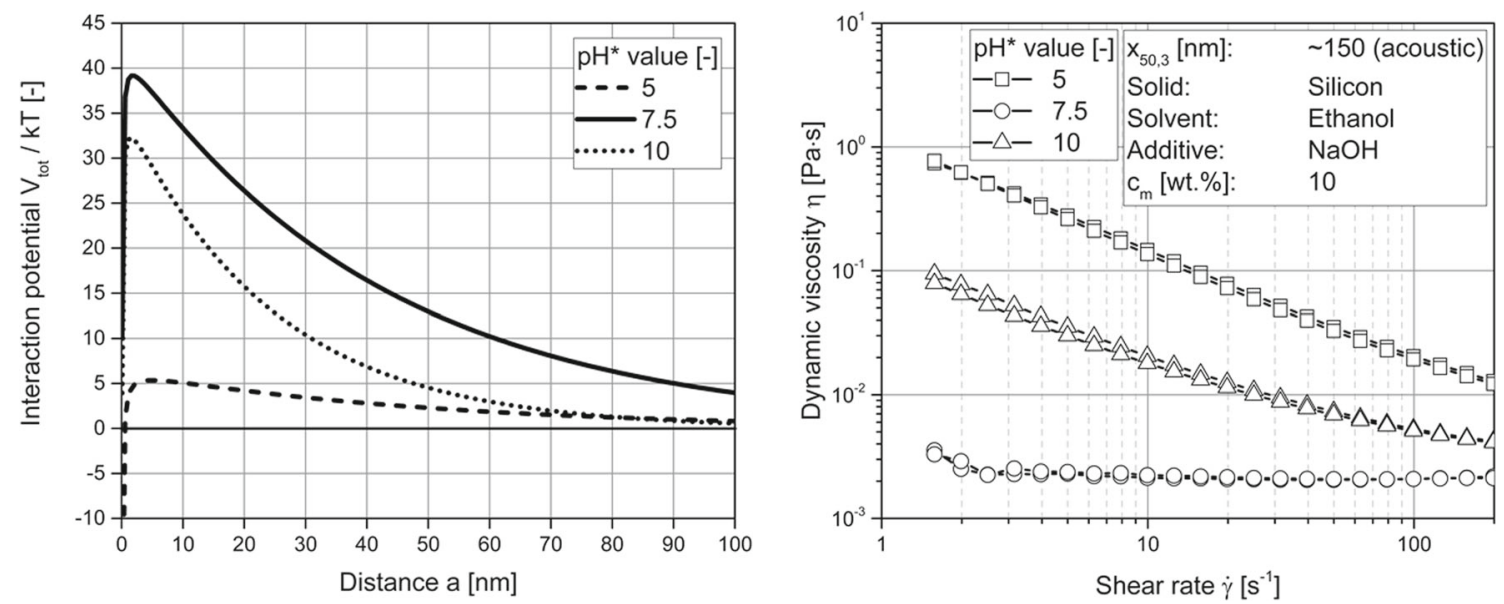

Fig. 4 Left: Normalized interaction potential dependent on the distance from the particle surface for different $\mathrm{pH}^{*}$ values; right: Dynamic viscosity as a function of shear rate for adjusted $\mathrm{pH}^{*}$ values 
$\mathrm{m}_{\mathrm{s}, \text { inorg }}=\mathrm{m}_{\mathrm{s}}-\mathrm{m}_{\text {loss }}$

Assuming that $\mathrm{m}_{\mathrm{s} \text {,inorg }}$ is the mass of pure silicon and taking into account the molecular weights of silicon $\mathrm{M}_{\mathrm{Si}}$ and $\mathrm{Si}_{3} \mathrm{~N}_{4}$ $\mathrm{M}_{\mathrm{Si3N} 4}$, the theoretical mass increase $\mathrm{m}_{\text {incr,theor }}$ was calculated regarding a stoichiometric reaction of silicon and nitrogen.

$3 \mathrm{Si}+2 \mathrm{~N}_{2} \stackrel{950^{\circ} \mathrm{C}}{\longrightarrow} \mathrm{Si}_{3} \mathrm{~N}_{4}$

$\mathrm{m}_{\text {incr,theor }}=\left(\frac{\mathrm{m}_{\mathrm{s}, \text { inorg }}}{3 \cdot \mathrm{M}_{\mathrm{Si}}}\right) \cdot \mathrm{M}_{\mathrm{Si} 3 \mathrm{~N} 4}$

The increased sample mass $m_{\text {incr }}$ analyzed by the TGA procedure was set in relation to the calculated $\mathrm{m}_{\text {incr,theor }}$ in order to obtain finally the metallic silicon content $\mathrm{c}_{\mathrm{Si}}$ of the sample.

$\mathrm{c}_{\mathrm{Si}}=\frac{\mathrm{m}_{\text {incr }}}{\mathrm{m}_{\text {incr.theor }}} \cdot 100 \mathrm{wt} . \%$

This value can range up to 100 wt.\%. For fine ground silicon it is lowered by degradation reactions due to the presence of especially $\mathrm{SiO}_{2}$ in the sample.

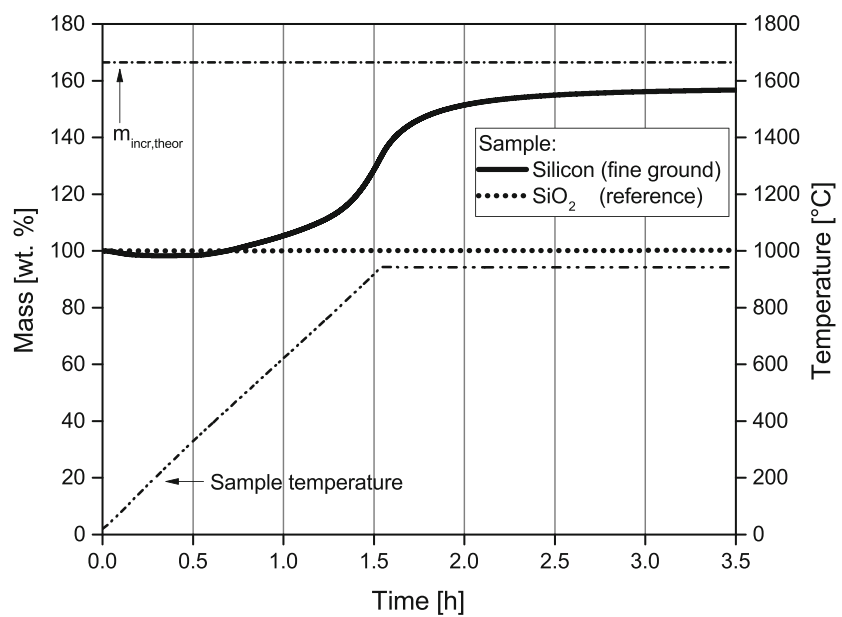

Fig. 7 Mass curve of a fine ground silicon sample during the TGA procedure in comparison to a $\mathrm{SiO}_{2}$ reference and a calculated theoretical mass increase for the formation of $\mathrm{Si}_{3} \mathrm{~N}_{4}$

In order to quantify the impact of electrostatic stabilization on the metallic silicon content $\mathrm{c}_{\mathrm{Si}}$, the $\mathrm{pH}^{*}$ value was changed during the fine grinding step. After a certain specific energy

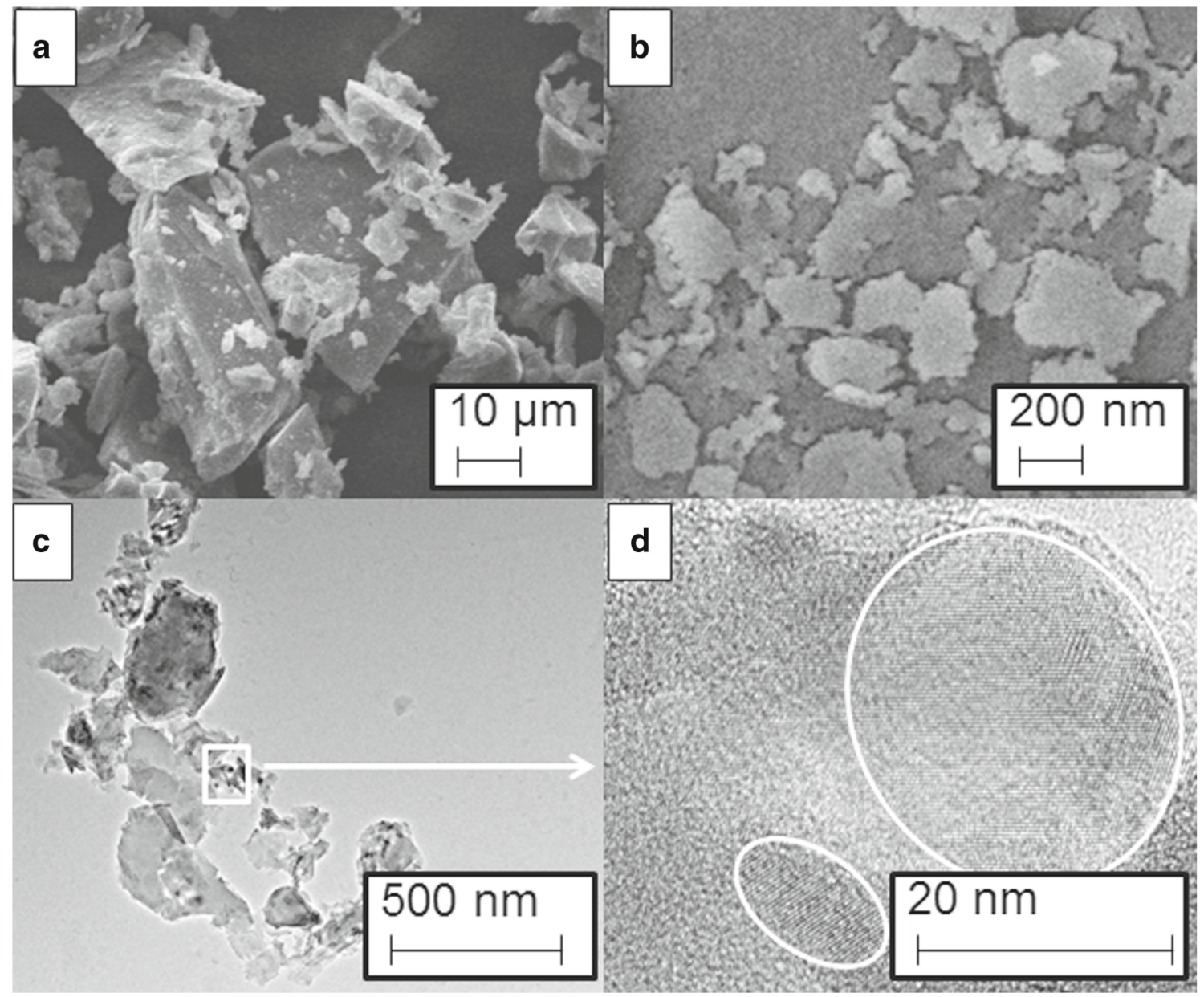

Fig. 6 SEM (a, b) and TEM pictures (c, d) of the feed material and the fine ground silicon particles: (a) feed material, (b, c, d) fine ground silicon particles $\left(\mathrm{x}_{50,3}: 150 \mathrm{~nm}\right.$, acoustic) 


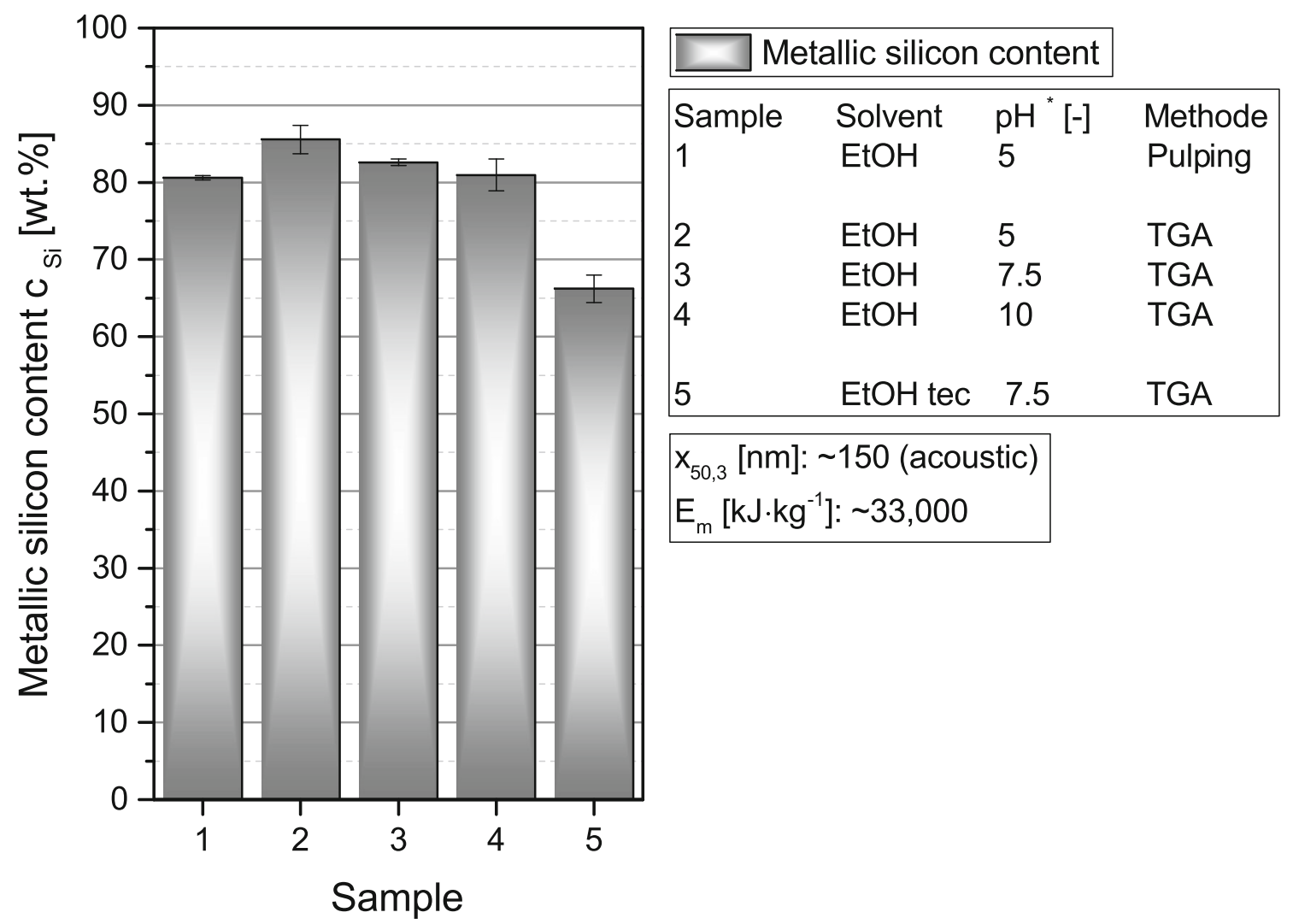

Fig. 8 Metallic silicon content $\mathrm{c}_{\mathrm{Si}}$ analyzed by pulping (DIN EN ISO 21068-2) for unstabilized silicon particles at $\mathrm{pH}$ * 5 (1) and by a TGA: (2) at $\mathrm{pH} * 5$, (3) at $\mathrm{pH}^{*} 7.5$, (4) at $\mathrm{pH}^{*} 10$ and (5) at $\mathrm{pH}^{*} 7.5$ in $\mathrm{EtOH}$ tec

input of $33,000 \mathrm{~kJ} \cdot \mathrm{kg}^{-1}$ a median primary particle size of $150 \mathrm{~nm}$ could be reached in every experiment. The metallic silicon content $\mathrm{c}_{\mathrm{Si}}$ was investigated by TGA measurements directly after each experiment and evaluated with a chemical pulping method according to DIN EN ISO 21068-2 (Fig. 8). The latter one is based on an etching reaction between silicon and $\mathrm{NaOH}$ in boiling water, which leads to the formation of hydrogen gas. The gas volume can be measured and the silicon content can be calculated assuming a stoichiometric reaction.

Due to the addition of $\mathrm{NaOH}$ to the suspension, small amounts of water are formed during the reaction of $\mathrm{NaOH}$ and ethanol, as well as solvated $\mathrm{Na}^{+}$Ions and $\mathrm{C}_{2} \mathrm{H}_{5} \mathrm{O}^{-}$. Especially the reaction between water and the silicon particle surface leads to increased formation of $\mathrm{SiO}_{2}$ and lowers $\mathrm{c}_{\mathrm{Si}}$ of the particles. Therefore, also the solvent quality which is mainly influenced by the water content was changed at $\mathrm{pH}^{*} 7.5$.

The samples with a $\mathrm{pH}^{*}$ value of 5 analyzed by pulping and TGA show a comparable $\mathrm{c}_{\mathrm{Si}}$ of 80 wt.\% and 85 wt. $\%$, respectively. At this point an uncertainly of 5 wt. $\%$ is identified, taking into account that the sample was analyzed some weeks later by pulping than by TGA. Therefore, influences regarding the storage of the suspension can't be excluded.
The addition of $\mathrm{NaOH}$ for $\mathrm{pH}^{*}$ values of 7.5 and 10 shows only a slightly decreasing $\mathrm{c}_{\mathrm{Si}}$ around $82 \mathrm{wt} . \%$. Thus, the small amount of additional water results only in a marginal lowering of $\mathrm{c}_{\mathrm{Si}}$. In contrast to that the change of the solvents quality by using $\mathrm{EtOH}$ tec shows a major reduction of $\mathrm{c}_{\mathrm{Si}}$ down to 66 wt.\%. Due to the increased water content of 4 wt.\% in this solvent a significant silicon oxidation occurs. The water content of the solvent is therefore a crucial parameter in order to achieve high metallic silicon content in the fine ground product.

\section{Conclusions}

A scaleable process route for the production of silicon nanoparticles within a two-step grinding procedure was investigated. The silicon nanoparticles show a flake-like morphology with an estimated thickness in the lower nanometer range and wide amorphous regions. At a specific energy input $E_{\mathrm{m}}$ of $33,000 \mathrm{~kJ} \cdot \mathrm{kg}^{-1}$ a median particle size $\mathrm{x}_{50,3}$ of $150 \mathrm{~nm}$ and a metallic silicon content $\mathrm{c}_{\mathrm{Si}}$ above 80 wt. $\%$ could be obtained.

Furthermore, electrostatic stabilization of the suspensions could be fulfilled by adding small amounts of $\mathrm{NaOH}$. These investigations were carried out by measuring the $\mathrm{pH}^{*}$ value, 
zeta potential $\zeta$, agglomerate size and rheological behavior of the suspensions. In addition the DLVO theory was applied for a detailed description of the stabilization mechanism. Stable suspensions were prepared by shifting the $\mathrm{pH}^{*}$ value to 7.5 due to the increase of repulsive particle-particle interaction.

The material composition was characterized by FT-IR analysis and the metallic silicon content $\mathrm{c}_{\mathrm{Si}}$ by a TGA procedure, which was evaluated applying a chemical pulping procedure according to DIN EN ISO 21068-2. It was shown that a surficial degradation of the silicon occurs during mechanical stressing due to oxidation reactions between reactive silicon surfaces and solvent molecules after particle breakage events. Especially the water content of the solvent influenced the extent of silicon degradation by massive lowering of the silicon content. In contrast different $\mathrm{pH}^{*}$ value adjustments in a range of $\mathrm{pH}^{*}$ 5 to 10 didn't result in significant differences regarding the metallic silicon content of the samples.

Further work will be done according to the scale-up of the grinding procedure by optimized formulation parameters. This will lead to a cost reduction for the production of higher amounts of silicon nanoparticles for various applications like for mass anode production of advanced lithium ion batteries. In addition, the interaction of silicon particle size, colloidal stability and oxidization could have impacts on the electrochemical anode performance.

Acknowledgements The Federal Ministry of Education and Research / Bundesministerium für Bildung und Forschung (BMBF) is gratefully acknowledged for the financial support. The authors also thank Christine Nowak (iPAT, TU Braunschweig) who assisted this research work, Bilal Temel (iPAT, TU Braunschweig) for XRD and TEM analysis, as well as Simone Schulze (iCTV, TU Braunschweig) and Peter Pfeiffer (ifW, TU Braunschweig) for SEM pictures.

Nomenclature a, [m], Distance; A, [J], Hamaker constant; $\mathrm{A}_{\mathrm{f}},[\mathrm{J}]$, Hamaker constant fluid (ethanol); $\mathrm{A}_{\mathrm{s}}$, [J], Hamaker constant solid (silica); $\mathrm{c}_{\mathrm{m}}$, [wt.\%], Solids concentration; $\mathrm{c}_{\mathrm{Si}}$, [wt.\%], Metallic silicon content; $\mathrm{E}_{\mathrm{m}},\left[\mathrm{kJ} \cdot \mathrm{kg}^{-1}\right]$, Specific Energy; F, [C·mol ${ }^{-1}$ ], Faraday constant; m, [g], Mass; $\mathrm{m}_{\mathrm{incr}}$, [g], Mass increase; $\mathrm{m}_{\text {incr,theor }}[\mathrm{g}]$, Theoretical mass increase; $\mathrm{m}_{\mathrm{loss}}$, [g], Mass loss; $\mathrm{m}_{\mathrm{s}}$, [g], Sample mass; $\mathrm{m}_{\mathrm{s}, \text { inorg }}$, [g], Inorganic sample mass; $\mathrm{M}_{\mathrm{Si}}$, $\left[\mathrm{g} \cdot \mathrm{mol}^{-1}\right]$, Molecular weight of silicon; $\mathrm{M}_{\mathrm{Si3N} 4},\left[\mathrm{~g} \cdot \mathrm{mol}^{-1}\right]$, Molecular weight of silicon nitride; $\mathrm{P},[\mathrm{W}]$, Power draw of the mill; $\mathrm{P}_{0}$, [W], No load measurement of the mill power draw; $\mathrm{Q}_{3}(\mathrm{x}),[\%]$, Particle size distribution sum weighted by volume; $\mathrm{q}_{3}(\mathrm{x})$, $\left[\mu \mathrm{m}^{-1}\right]$, Particle size density distribution weighted by volume; $\mathrm{r},[\mathrm{m}]$, Particle radius; $\mathrm{R},\left[\mathrm{J} \mathrm{Kmol}^{-1}\right]$, Gas constant; $\mathrm{T},\left[{ }^{\circ} \mathrm{C}\right]$, Temperature; $t$, [s], time; $\mathrm{V}_{\mathrm{A}}$, [J], Attractive van der Vaals potential; $\mathrm{V}_{\mathrm{R}}$, [J], Repulsive electrostatic potential; $\mathrm{V}_{\text {tot }},[\mathrm{J}]$, Total interaction potential; $\mathrm{x},[\mathrm{nm}]$ $[\mu \mathrm{m}]$, Particle size; $\mathrm{x}_{50,3},[\mathrm{~nm}]$, Volume based median particle size; $\dot{\gamma},\left[\mathrm{s}^{-1}\right]$, shear rate; $\varepsilon,[-]$, Dielectric coefficient; $\varepsilon_{0},\left[\mathrm{C} \cdot \mathrm{V}^{-1} \cdot \mathrm{m}^{-1}\right]$, Electric constant; $\zeta$, $[\mathrm{mV}]$, Zeta potential; $\eta$, $[\mathrm{Pa} \cdot \mathrm{s}]$, Dynamic viscosity; $\mathrm{\kappa},\left[\mathrm{m}^{-3}\right]$, Debye parameter; $v,[-]$, Valence; $\Psi_{0},[\mathrm{~V}]$, Surface potential

Open Access This article is distributed under the terms of the Creative Commons Attribution 4.0 International License (http:// creativecommons.org/licenses/by/4.0/), which permits unrestricted use, distribution, and reproduction in any medium, provided you give appropriate credit to the original author(s) and the source, provide a link to the Creative Commons license, and indicate if changes were made.

Publisher's Note Springer Nature remains neutral with regard to jurisdictional claims in published maps and institutional affiliations.

\section{References}

1. Barth N, Zimmermann M, Becker AE, Graumann T, Garnweitner G, Kwade A (2015) Influence of TiO2 nanoparticle synthesis on the properties of thin coatings. Thin Solid Films 574:20-27. https://doi. org/10.1016/j.tsf.2014.11.038

2. Steiner D, Finke JH, Kwade A (2018) Instant ODFs - development of an intermediate, nanoparticle-based product platform for individualized medication. Eur J Pharm Biopharm 126:149-158. https:// doi.org/10.1016/j.ejpb.2017.04.014

3. Hesselbach J, Barth N, Lippe K, Schilde C, Kwade A (2015) Process chain and characterisation of nanoparticle enhanced composite coatings. Adv Powder Technol 26(6):1624-1632. https://doi. org/10.1016/j.apt.2015.09.006

4. Jux M, Finke B, Mahrholz T, Sinapius M, Kwade A, Schilde C (2017) Effects of $\mathrm{Al}(\mathrm{OH}) \mathrm{O}$ nanoparticle agglomerate size in epoxy resin on tension, bending, and fracture properties. J Nanopart Res 19(4):241. https://doi.org/10.1007/s11051-017-3831-9

5. Pillai S, Catchpole KR, Trupke T, Zhang G, Zhao J, Green MA (2006) Enhanced emission from Si-based light-emitting diodes using surface plasmons. Appl Phys Lett 88(16):161102. https:// doi.org/10.1063/1.2195695

6. Boyraz O, Jalali B (2005) Demonstration of directly modulated silicon Raman laser. Opt Express 13(3):796. https://doi.org/10. 1364/OPEX.13.000796

7. Wang L, Reipa V, Blasic J (2004) Silicon nanoparticles as a luminescent label to DNA. Bioconjug Chem 15(2):409-412. https://doi. org $/ 10.1021 / \mathrm{bc} 030047 \mathrm{k}$

8. Tasciotti E, Liu X, Bhavane R, Plant K, Leonard AD, Price BK, Cheng MMC, Decuzzi P, Tour JM, Robertson F, Ferrari M (2008) Mesoporous silicon particles as a multistage delivery system for imaging and therapeutic applications. Nat Nanotechnol 3(3):151157. https://doi.org/10.1038/nnano.2008.34

9. Park J-H, Gu L, von MG et al (2009) Biodegradable luminescent porous silicon nanoparticles for in vivo applications. Nat Mater 8(4):331-336. https://doi.org/10.1038/nmat2398

10. Bimbo LM, Mäkilä E, Laaksonen T, Lehto VP, Salonen J, Hirvonen J, Santos HA (2011) Drug permeation across intestinal epithelial cells using porous silicon nanoparticles. Biomaterials 32(10):26252633. https://doi.org/10.1016/j.biomaterials.2010.12.011

11. Näkki S, Rytkönen J, Nissinen T, Florea C, Riikonen J, Ek P, Zhang H, Santos HA, Närvänen A, Xu W, Lehto VP (2015) Improved stability and biocompatibility of nanostructured silicon drug carrier for intravenous administration. Acta Biomater 13:207-215. https:// doi.org/10.1016/j.actbio.2014.11.019

12. Zhang K, Loong SLE, Connor S et al (2005) Complete tumor response following intratumoral 32P BioSilicon on human hepatocellular and pancreatic carcinoma xenografts in nude mice. Clin Cancer Res 11(20):7532-7537. https://doi.org/10.1158/10780432.CCR-05-0400

13. Drahi E, Blayac S, Saunier S, Valdivieso F, Bartholin MC, Grosseau P, Benaben P (2011) Recovering functional properties of solution processed silicon thin-films. Energy Procedia 10:144148. https://doi.org/10.1016/j.egypro.2011.10.167 
14. Drahi E, Gupta A, Blayac S, Saunier S, Benaben P (2014) Characterization of sintered inkjet-printed silicon nanoparticle thin films for thermoelectric devices. Phys Status Solidi A 211(6):13011307. https://doi.org/10.1002/pssa.201300180

15. Riecke A (2017) Thermische Umwandlung dünner SiliziumSchichten. Friedrich-Alexander-Universität Erlangen-Nürnberg, Dissertation

16. Ashuri M, He Q, Shaw LL (2016) Silicon as a potential anode material for Li-ion batteries: where size, geometry and structure matter. Nanoscale 8(1):74-103. https://doi.org/10.1039/ c5nr05116a

17. Hou X, Zhang M, Wang J, Hu S, Liu X, Shao Z (2015) High yield and low-cost ball milling synthesis of nano-flake $\mathrm{Si} @ \mathrm{SiO} 2$ with small crystalline grains and abundant grain boundaries as a superior anode for Li-ion batteries. J Alloys Compd 639:27-35. https://doi. org/10.1016/j.jallcom.2015.03.127

18. Li F-S, Wu Y-S, Chou J, Wu NL (2015) A dimensionally stable and fast-discharging graphite-silicon composite Li-ion battery anode enabled by electrostatically self-assembled multifunctional polymer-blend coating. Chem Commun (Camb) 51(40):84298431. https://doi.org/10.1039/c4cc09825k

19. X-y Z, Song W-L, Liu Z et al (2017) Geometric design of micronsized crystalline silicon anodes through in situ observation of deformation and fracture behaviors. J Mater Chem A 5(25):1279312802. https://doi.org/10.1039/C7TA02527K

20. Liu XH, Zhong L, Huang S, Mao SX, Zhu T, Huang JY (2012) Size-dependent fracture of silicon nanoparticles during lithiation. ACS Nano 6(2):1522-1531. https://doi.org/10.1021/nn204476h

21. Reindl A, Aldabergenova S, Altin E, Frank G, Peukert W (2007) Dispersing silicon nanoparticles in a stirred media mill - investigating the evolution of morphology, structure and oxide formation. Phys Stat Sol (A) 204(7):2329-2338. https://doi.org/10.1002/pssa. 200622557

22. Reindl A, Voronov A, Gorle PK, Rauscher M, Roosen A, Peukert W (2008) Dispersing and stabilizing silicon nanoparticles in a lowepsilon medium. Colloids Surf A Physicochem Eng Asp 320(1-3): 183-188. https://doi.org/10.1016/j.colsurfa.2008.01.045

23. Verwey EJW, Overbeek JZG (1948) Theory of the stability of lyophobic colloids: the interaction of sol particles having an electric double layer. Elsevier Publishing Company, New York Amsterdam - London - Brussels

24. Barth N, Schilde C, Kwade A (2014) Influence of electrostatic particle interactions on the properties of particulate coatings of titanium dioxide. J Colloid Interface Sci 420:80-87. https://doi.org/10. 1016/j.jcis.2014.01.005

25. Menon M, Decourcelle S, Ramousse S, Larsen PH (2006) Stabilization of ethanol-based alumina suspensions. J American
Ceramic Society 89(2):457-464. https://doi.org/10.1111/j.15512916.2005.00744.x

26. Mussini T, Covington AK, Longhi P, Rondinini S (1985) Criteria for standardization of $\mathrm{pH}$ measurements in organic solvents and water + organic solvent mixtures of moderate to high permittivities. Pure Appl Chem 57(6):865-876. https://doi.org/10.1351/ pac198557060865

27. Müller RH, Mehnert W, Paulke B-R (1996) Zetapotential und Partikelladung in der Laborpraxis. Einführung in die Theorie, Praktische Meßdurchführung, Dateninterpretation. Wissenschaftliche Verlagsgesellschaft mbH Stuttgart, Stuttgart

28. Riikonen J, Salomäki M, van Wonderen J, Kemell M, Xu W, Korhonen O, Ritala M, MacMillan F, Salonen J, Lehto VP (2012) Surface chemistry, reactivity and pore structure of porous silicon oxidized by various methods. Langmuir 28(28):10573-10583. https://doi.org/10.1021/la301642w

29. Wayner DDM, Wolkow RA (2002) Organic modification of hydrogen terminated silicon surfaces1. J Chem Soc Perkin Trans 2(1):2334. https://doi.org/10.1039/b1007041

30. Newton TA, Huang Y-C, Lepak LA, Hines MA (1999) The sitespecific reactivity of isopropanol in aqueous silicon etching: controlling morphology with surface chemistry. J Chem Phys 111(20): 9125-9128. https://doi.org/10.1063/1.479386

31. Wang G, Sarkar P, Nicholson PS (1996) Influence of acidity on the electrostatic stability of alumina suspensions in ethanol. J Am Ceram Soc

32. Lagaly G, Schulz O, Zimehl R (1997) Dispersionen und Emulsionen: Eine Einführung in die Kolloidik feinverteilter Stoffe einschließlich der Tonminerale. Steinkopff, Heidelberg

33. Reindl A, Peukert W (2008) Intrinsically stable dispersions of silicon nanoparticles. J Colloid Interface Sci 325(1):173-178. https:// doi.org/10.1016/j.jcis.2008.05.042

34. Israelachvili JN (2015) Van der Waals forces between particles and surfaces. In: Israelachvili $\mathrm{JN}$ (ed) Intermolecular and surface forces3rd edn. Elsevier Science, Saint Louis, pp 253-289

35. Schmidt VM (2003) Elektrochemische Verfahrenstechnik. WILEY$\mathrm{VCH}$, Weinheim

36. Tao H-C, Yang X-L, Zhang L-L, Ni SB (2014) Double-walled coreshell structured Si@SiO2@C nanocomposite as anode for lithiumion batteries. Ionics 20(11):1547-1552. https://doi.org/10.1007/ s11581-014-1138-8

37. Schierning G, Theissmann R, Wiggers H, Sudfeld D, Ebbers A, Franke D, Witusiewicz VT, Apel M (2008) Microcrystalline silicon formation by silicon nanoparticles. J Appl Phys 103(8):84305. https://doi.org/10.1063/1.2903908 